\title{
Imobilização de enzimas de milho maltado em gel
}

\author{
Gel immobilization of enzymes from malted corn
}

\author{
Rosa Luísa de Farias Oliveira Bezerra e SILVA ${ }^{1}$, Roberto Rodrigues de SOUZA ${ }^{1}$, \\ José Carlos Curvelo SANTANA², Elias Basile TAMBOURGI ${ }^{2 *}$
}

\section{Resumo}

Este trabalho objetivou a otimização da imobilização das enzimas amilases extraídas do malte do milho, usando alginato de sódio. A concentração do malte no extrato, a porcentagem de alginato de sódio e o $\mathrm{pH}$ foram usados como fatores que influenciam na imobilização das enzimas. Os resultados mostraram que as melhores condições de imobilização foram obtidas quando se usou as soluções de malte de milho em duas faixas de concentrações, uma entre 3,75 a 5 g.L $\mathrm{L}^{-1}$ e outra entre 15 a 16,25 g.L $\mathrm{L}^{-1}$, em pH entre 4,83 a 6,6 e $4 \%$ (m/v) de alginato de sódio, condições nas quais se conseguiu imobilizar $100 \%$ das enzimas com baixa perda de atividade. Este trabalho mostrou como se obter amilases de malte de milho imobilizadas por oclusão em alginato de sódio e que podem ser usadas em processos industriais de hidrólise de amido.

Palavras-chave: imobilização; amilases; alginato de sódio; malte de milho; oclusão; biocatalisador.

\begin{abstract}
$\bigotimes$ is work aimed at optimizing the immobilization of amylases obtained from corn malt by the occlusion method with sodium alginate. Corn malt concentration, sodium alginate mass percentage and $\mathrm{pH}$ were used as factors that influence enzyme immobilization. $\mathbb{\mathrm { e }}$ results showed that the best immobilization conditions were obtained at two ranges of corn malt concentration, one between $3.75-5$ g. $\mathrm{L}^{-1}$ and the other between 15-16.25 g.L $\mathrm{L}^{-1}$, at $\mathrm{pH}$ between $4.83-6.6$ and at $4 \%(\mathrm{~m} / \mathrm{m})$ sodium alginate. In these conditions, $100 \%$ of the enzymes were immobilized with a low loss of activity. $\mathbb{Q}$ is work showed how to obtain immobilized corn malt amylases that can be used in industrial processes of starch hydrolysis by occlusion in sodium alginate.
\end{abstract}

Keywords: immobilization; amylases; sodium alginate; corn malt; occlusion; bio-catalyst.

\section{Introdução}

As enzimas $\bigotimes$-amilase (EC 3.3.1.1; $\alpha$-1,4 glicano, 4-glicanohidroxilase) e $\beta$-amilase (EC 3.2.1.1, $\alpha-1,4$, glicanomaltohidrolase) são obtidas geralmente por microrganismos ou por malte de cevada (embora qualquer cereal germinado as contenha), suas temperaturas e seus $\mathrm{pHs}$ ótimos variam entre 75 e $55^{\circ} \mathrm{C}$ e 4,8 e 6,5; respectivamente, embora estas faixas dependam da origem destas enzimas. O uso fundamental das amilases está na hidrólise do amido, principalmente na indústria de pani冈cação; no pré-cozimento de cereais nas indústrias de fermentação, para a produção de álcool e bebidas alcoólicas; na fabricação de xaropes de glicose, via hidrólise pelas amilases; no preparo de gomas de dextrinas, usadas para acabamento de papéis e tecidos; dentre outros (BIAZUS et al., 2005a; b; 2006a; b; c; SANTANA, 2003).

As enzimas estão sujeitas à inativação por fatores químicos, físicos ou biológicos, podendo esta ocorrer quando estocadas ou durante o uso. Para que a catálise seja e区ciente em um determinado processo, há a necessidade de protegê-las da interação com o solvente, meio no qual é realizada a reação, pois o mesmo poderia provocar a inativação, impossibilitando a catálise da reação. Frente a este problema, novas técnicas de imobilização têm sido desenvolvidas para fornecer a estabilidade das enzimas e facilitar sua recuperação e reutilização (DALLA-VECCHIA et al., 2004).

As técnicas de imobilização de enzimas \caram mais conhecidas a partir dos anos 60 (BORZANI et al., 2001), e desde então vem sido estudada a imobilização de enzimas como as lipases, em sílica de porosidade controlada e por outros métodos por Cruz (2000) e Soares (2000); outros autores imobilizaram lipases por diversos métodos (CASTRO; ANDERSIN, 1995; MALCATA et al., 1990); as enzimas amilases foram imobilizadas em membranas (BAYRAMOGLU et al., 2004) e as enzimas inulinases por diversos métodos (GASPARI et al., 1999). A imobilização também é aplicada em microrganismos para facilitar seu uso em fermentação contínua (ROBLE et al., 2000).

A técnica de imobilização de enzimas trouxe como vantagens imediatas a possibilidade de reaproveitamento do catalisador, o uso em processos contínuos, o aumento da estabilidade da enzima, a regeneração e o reuso do catalisador, e a redução dos custos (BORZANI et al., 2001; CASTRO; ANDERSON, 1995; GOODENOUGH; LAW, 1991; KOURKOUTAS et al., 2004; LIM et al., 2003; MALCATA et al., 1990; OLSON; RICHHARDSON, 1974; ROBLE et al., 2000). De outra parte, as desvantagens mais

Recebido para publicação em 19/4/2007

Aceito para publicação em 19/10/2007 (002472)

${ }^{1}$ Departamento de Engenharia de Sistemas Químicos, Faculdade de Engenharia Química, Universidade Estadual de Campinas - UNICAMP, Campinas - SP, Brasil

${ }^{2}$ Departamento de Engenharia Química, Centro de Ciências Exatas e Tecnologia, Universidade Federal de Sergipe - UFS, São Cristóvão - SE, Brasil

${ }^{*}$ A quem a correspondência deve ser enviada 
notórias seriam a aleatoriedade da interação suporte-enzima, a dessorção das enzimas com o uso, a redução da atividade catalítica devido aos efeitos difusionais, de microambiente e estéreoconformacionais (BORZANI et al., 2001; REGULY, 2000).

A imobilização de enzimas por oclusão ou inclusão física em uma matriz é um método brando e não desnaturante, pois a enzima é retida e aprisionada na estrutura do gel de polímero. Este é reforçado por ligações cruzadas a partir da dispersão aquosa, a qual pode conter uma ou mais enzimas. Desta forma, a enzima não está ligada quimicamente ao suporte e sua molécula permanece intacta. As desvantagens da imobilização por inclusão são: difusão ou exsudação contínua da enzima, devido ao diâmetro não uniforme dos poros do gel; acesso reduzido do substrato à enzima; perda de atividade enzimática devido aos radicais livres, produzidos durante a reação de polimerização. O método tem sido usado para imobilizar papaína, tripsina, $\alpha$-e $\beta$-amilase, glicose-oxidase, uréase, entre outras enzimas (REGULY, 2000).

Este trabalho objetivou a otimização da imobilização de enzimas amilases extraídas do malte do milho usando o método de oclusão em alginato de sódio, tendo como variáveis a concentração do malte no extrato, a porcentagem de alginato de sódio e o pH do meio, para produzir uma nova forma de biocatalisador de amido com boa atividade enzimática, estável ao meio reacional, que possa ser aplicada em processos contínuos e que permita o seu reaproveitamento.

\section{Material e métodos}

\subsection{Materiais}

As sementes de milho foram adquiras junto à EMBRAPA (Tabuleiros Costeiro), sediada em Aracaju-SE. O ácido ofosfórico PA foi adquirido junto a Synth (Diadema-SP, Brasil), o acetato de sódio PA, o ácido acético PA, o ácido di-nitrosalicílico (DNS), o álcool etílico PA e o alginato de sódio foram adquiridos da VETEC (São Paulo, Brasil), enquanto que o azul brilhante de Comassie-G e o amido solúvel foram adquiridos da MERCK (Berlim, Alemanha).

\subsection{Obtenção das enzimas}

As sementes de milho foram selecionadas, pesadas, lavadas, postas em béquer contendo água para que estas absorvessem entre 40 a $45 \%$ de seu peso inicial em umidade. Depois as sementes úmidas foram colocadas em meio germinativo em escala laboratorial em condições normais de temperatura e pressão (27 ${ }^{\circ} \mathrm{C}$ e pressão ambiente), por aproximadamente 4 a 5 dias. $\mathrm{O}$ malte foi seco na temperatura de $54^{\circ} \mathrm{C}$, triturado, armazenado em sacos plásticos e guardado a $10 \pm 1{ }^{\circ} \mathrm{C}$ (SANTANA, 2003). Uma solução $2 \%$ de malte de milho a pH 5 (em tampão fosfato) foi preparada para uso nos biorreatores. Seu teor de proteína total foi quanti冈cado pelo método de Bradford (1976).

\subsection{Determinação da atividade enzimática}

O meio reacional continha $20 \mathrm{~mL}$ de uma solução de amido solúvel a 2\% e pH 4,8 (tampão acetato) e $5 \mathrm{~mL}$ de água destilada a $32 \pm 2{ }^{\circ} \mathrm{C}$. Para determinação da atividade enzimática foram adicionados a este meio, cerca de $500 \mu \mathrm{L}$ da solução de malte de milho $\left(A_{\text {inicial }}=\right.$ atividade inicial das amilases contidas no malte) antes da imobilização, ou cerca de $500 \mu \mathrm{L}$ do líquido de lavagem das esferas de enzimas imobilizadas (filtrado) $\left(A_{\text {filtrado }}=\right.$ atividade das amilases contidas no Dltrado) ou cerca de $0,5 \mathrm{~g}$ de esferas de enzimas imobilizadas $\left(A_{\text {imobilizada }}=\right.$ atividade das amilases imobilizadas). Após 10 minutos de reação coletaram-se amostras (em triplicata), que foram postas em cubetas fotométricas, seu volume completado a $2 \mathrm{~mL}$ com água destilada e $3 \mathrm{~mL}$ do reagente DNS foi adicionado. Foi feito ensaio em branco com água. As cubetas foram levadas ao aquecimento por 5 minutos a $100^{\circ} \mathrm{C}$, e em seguida resfriadas e analisadas em espectrofotômetro a $540 \mathrm{~nm}$. As concentrações de açúcares redutores (em g glicose/L) foram obtidas pelo uso de uma curva de calibração previamente elaborada. A unidade de atividade enzimática foi dada pela quantidade de glicose gerada (em $\mu \mathrm{mol})$ por minuto por miligrama de proteína total (U.mg-1) (BIAZUS et al., 2006b; c).

\subsection{Imobilização por oclusão em matriz}

Foram preparadas soluções de malte de milho em concentração $\left(C_{\text {malte }}\right)$ e pHs da solução previamente planejados (Tabela 1). O volume utilizado das soluções foi de $10 \mathrm{~mL}$. Adicionou-se a estas soluções de malte de milho a pHs planejados uma certa massa de alginato de sódio de maneira a se obter uma porcentagem (malginato, massa/volume) também planejada (Tabela 1), misturando-se até a formação de uma pasta. Essa pasta foi gotejada, utilizando-se uma micropipeta, em uma solução de $\mathrm{CaCl}_{2}$ a 4\%, obtendo-se esferas das enzimas imobilizadas no alginato de sódio. As esferas formadas foram separadas da solução de $\mathrm{CaCl}_{2}$ por \ltração em papel 冈ltro 40 e lavadas com água destilada (CRUZ, 2000; GASPARI et al., 1999; REGULY, 2000; SOARES, 2000).

O planejamento usado para a realização deste experimento está apresentado na Tabela 2 . Ele foi do tipo $2^{3-1}$, com triplicata no ponto central e valores axiais nos três eixos, tendo como respostas o rendimento da imobilização $\left(R_{\text {imobilização }}\right)$ e a porcentagem de perda ou redução da atividade $(\% P)$. Sua codi $\$ cação foi a seguinte (Equações 1, 2 e 3):

$$
\begin{aligned}
& x_{1}=\frac{C_{\text {malte }}-10}{5} \\
& x_{2}=\frac{M_{\text {alginato }}-0,3}{0,1} \\
& x_{3}=p H-6
\end{aligned}
$$

O rendimento da imobilização $\left(R_{\text {imobilizacãa }}\right)$ das amilases de malte de milho foi obtido pela Equação 4 e a porcentagem de perda ou redução da atividade pela Equação 5:

$$
\begin{aligned}
& R_{\text {imobilização }}=\left(\frac{A_{\text {imobilizada }}-A_{\text {filtrado }}}{A_{\text {inicial }}}\right) * 100 \\
& \% P=\left(1-\left[\frac{A_{\text {imobilizada }}+A_{\text {filtrado }}}{A_{\text {inicial }}}\right]\right) * 100
\end{aligned}
$$


Tabela 1. Matriz de planejamento para a otimização da imobilização das enzimas amilases por oclusão em matriz.

\begin{tabular}{|c|c|c|c|c|c|c|c|c|}
\hline Ensaios & $x_{1}$ & $x_{2}$ & $x_{3}$ & $C_{\text {malte }}\left(\mathrm{g} \cdot \mathrm{L}^{-1}\right)$ & $M_{\text {alginato }}(\mathrm{g})^{\star}$ & $\mathrm{pH}$ & $R_{\text {imobilização }}$ & $\% I$ \\
\hline 1 & -1 & -1 & 1 & 5 & 0,2 & 7 & 7,839 & 100,0 \\
\hline 2 & 1 & -1 & -1 & 15 & 0,2 & 5 & 100,0 & 0,000 \\
\hline 3 & -1 & 1 & -1 & 5 & 0,4 & 5 & 100,0 & 0,000 \\
\hline 4 & 1 & 1 & 1 & 15 & 0,4 & 7 & 0,000 & 100,0 \\
\hline 5 & 0 & 0 & 0 & 10 & 0,3 & 6 & 100,0 & 53,40 \\
\hline 6 & 0 & 0 & 0 & 10 & 0,3 & 6 & 100,0 & 64,76 \\
\hline 7 & 0 & 0 & 0 & 10 & 0,3 & 6 & 100,0 & 65,42 \\
\hline 8 & $-1,414$ & 0 & 0 & 2,930 & 0,3 & 6 & 0,00 & 0,000 \\
\hline 9 & 1,414 & 0 & 0 & 17,05 & 0,3 & 6 & 0,00 & 0,000 \\
\hline 10 & 0 & $-1,414$ & 0 & 10 & 0,1586 & 6 & 50,50 & 100,0 \\
\hline 11 & 0 & 1,414 & 0 & 10 & 0,4414 & 6 & 100,0 & 100,0 \\
\hline 12 & 0 & 0 & $-1,414$ & 10 & 0,3 & 4,830 & 7,839 & 100,0 \\
\hline 13 & 0 & 0 & 1,414 & 10 & 0,3 & 7,414 & 100,0 & 0,000 \\
\hline
\end{tabular}

${ }^{*}$ Massa de alginato de sódio usada para cada $10 \mathrm{~mL}$ de solução de malte de milho.

Tabela 2. Resultados da avaliação ANOVA do modelo do rendimento da imobilização das amilases do malte de milho por oclusão usando o alginato de sódio.

\begin{tabular}{|c|c|c|c|c|c|}
\hline $\begin{array}{l}\text { Fonte de } \\
\text { variação }\end{array}$ & $\begin{array}{c}\text { Soma } \\
\text { quadrática }\end{array}$ & $\begin{array}{l}\text { Graus de } \\
\text { liberdade }\end{array}$ & $\begin{array}{c}\text { Média } \\
\text { quadrática }\end{array}$ & $F_{\text {calc }}$ & $F_{t a b}$ \\
\hline Regressão & 25543,4 & 8 & 3192,91 & 6,471 & 6 \\
\hline Resíduos & 1973,6 & 4 & 493,406 & - & - \\
\hline Falta de ajuste & 1973,6 & 2 & 986,812 & - & 19 \\
\hline Erro puro & 0,000 & 2 & 0,000 & - & - \\
\hline Total & 27517,0 & 12 & - & - & - \\
\hline \multicolumn{6}{|c|}{ \% de variância explicável $=92,828$} \\
\hline \multicolumn{6}{|c|}{$\%$ máxima variância explicável $=100,00$} \\
\hline \multicolumn{3}{|c|}{ Coe®ciente de determinação $\left(\mathrm{R}^{2}\right)=$} & 0,9283 & & \\
\hline
\end{tabular}

Modelos empíricos foram ajustados aos dados, enquanto que a avaliação dos seus ajustes foram feitas pela metodologia de análise de variância (ANOVA) e a otimização dos experimentos foi feita pela metodologia de análise de superfície de respostas (RSM). As superfícies de resposta e as curvas de nível foram geradas em Software Statistica for Windows 6.0 (BARROS NETO et al., 1995; 2001; BIAZUS et al., 2005a; b; 2006a).

\section{Resultados e discussão}

A Tabela 1 apresenta os ensaios realizados durante a execução deste experimento, na qual encontramos os valores reais da concentração do malte $\left(C_{\text {malte }}\right)$, da porcentagem de alginato de sódio $\left(M_{\text {alsinato }}\right)$ e do $\mathrm{pH}$ e seus respectivos valores na forma de variáveis codiðcadas $\left(x_{1}, x_{2}, x_{3}\right)$, bem como as respostas, o rendimento da imobilização $\left(R_{\text {imobilizacăo }}\right)$ e a porcentagem de perda ou redução $(\% P)$ da atividade enzimática das amilases do malte de milho. Percebe-se que os maiores valores de rendimento de imobilização foram encontrados nos ensaios 2, 3, 5, 6, 7 e 13, onde 100\% das enzimas foram imobilizadas. Estes valores são muito superiores aos encontrados por Bayramoglu et al. (2004), Gaspari et al. (1999) e Lim et al. (2003), que conseguiram imobilizar menos de $80 \%$ das amilases em seus trabalhos. Pereira et al. (2003) imobilizaram lipases em quitosana e obtiveram um rendimento inferior a $17 \%$. Day et al. (2003) conseguiram um rendimento de imobilização de $\alpha$-amilase em alginato de sódio de uma linhagem de Bacillus circulans GRS313 de cerca de 75\%.
Já Brena et al. (1993) imobilizaram apenas 19\% de $\beta$-amilase de batata em tiosulfonato de agarose. Entretanto, apenas nos ensaios 2, 3 e 13 não se nota inibição da atividade das enzimas imobilizadas pelo alginato de sódio. Reguly (2000) cita que a redução da atividade enzimática das enzimas imobilizadas por oclusão ocorre devido à difusão ou exsudação contínua da enzima, ao acesso reduzido do substrato à enzima e à presença de radicais livres produzidos durante a reação de polimerização. Bayramoglu et al. (2004) citam que a forma como as enzimas são aprisionadas no retículo do gel pode deixar de expor seus sítios ativos ao substrato, o que impede a realização da catálise, reduzindo a atividade da enzima imobilizada.

A Tabela 2 apresenta a avaliação do modelo que mais se ajustou aos dados de rendimento da imobilização (Equação 6), pela metodologia ANOVA. Nota-se que não há valor de $F_{\text {calc }}$ para a falta de ajuste porque não houve desvio nos pontos centrais, já que os três rendimentos foram iguais, o que impedirá a sua avaliação. De acordo com Barros Neto et al. (1995 e 2001), os valores das porcentagens de variância e do coe冈ciente de determinação devem estar próximos de 100\% e 1,0; respectivamente, e as relações entre os valores do teste $F$ para a regressão $\left(F_{\text {calc }} / F_{\text {tab }}\right)$ e para a falta de ajuste $\left(F_{\text {tab }} / F_{\text {calc }}\right)$ devem ser superiores a 4 . Assim, como estes valores estão próximos aos valores ótimos determinados pela metodologia, logo o modelo possui uma reduzida quantidade de erros, desta forma pode-se a\rmar que o modelo empírico é signið cativo estatisticamente e os dados experimentais se ajustam à curva.

A Equação 6 mostrada abaixo é o modelo que mais se ajustou, obtido após regressão quadrática dos dados experimentais da imobilização das amilases de malte de milho por oclusão em alginato de sódio. Nota-se uma dependência quadrática do rendimento da imobilização sob a influência da concentração do malte $\left(x_{1}\right)$, da massa do alginato de sódio $\left(x_{2}\right)$ e do $\mathrm{pH}\left(x_{3}\right)$. Como o programa usado não consegue fazer análises de influências para modelos quadráticos se o planejamento é fracionado, esta análise não foi feita.

$$
\begin{aligned}
& R_{\text {imobilizacăo } 0}=91,20+17,50 \cdot x_{2}+32,59 \cdot x_{3}-39,01 \cdot x_{1}^{2}-1,374 \cdot x_{2}^{2}- \\
& 12,04 \cdot x_{3}^{2} \ldots+\ldots-80,63 \cdot x_{1} * x_{2}-19,46 \cdot x_{1} * x_{3}-1,960 \cdot x_{2} * x_{3}
\end{aligned}
$$


A Tabela 3 apresenta os resultados da avaliação ANOVA do ajuste do modelo (Equação 7) aos dados da perda ou redução da atividade enzimática. Os valores das porcentagens de variância, do coe凶ciente de determinação e dos teste $F$ para a regressão $\left(F_{\text {calc }} / F_{\text {tab }}\right)$ e para a falta de ajuste $\left(F_{\text {tab }} / F_{\text {calc }}\right)$ encontram-se muito próximos dos dados citados como corretos pela metodologia

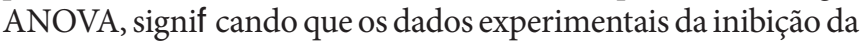
atividade estão ajustados ao modelo otimizado e que o modelo empírico é signi冈cativo estatisticamente (BARROS NETO et al., 1995; 2001; BIAZUS et al., 2005a; b; 2006a).

A Equação 7, mostrada abaixo, representa o modelo empírico obtido após regressão quadrática dos dados experimentais da perda ou redução da atividade das amilases de malte de milho por oclusão em alginato de sódio.

$\% P=59,88-35,36 \cdot x_{3}-28,96 \cdot x_{1}^{2}+21,06 \cdot x_{2}^{2}-3,951 \cdot x_{3}^{2}+85,36 \cdot x_{1} * x_{2}$

A otimização da imobilização das amilases de malte de milho será realizada usando duas respostas combinadas, o rendimento da imobilização e a inativação das enzimas imobilizadas. Em princípio, a análise será feita em pares de Figuras com curvas do tipo RSMs, sendo uma para análises do rendimento e outra para análise da inibição, ambas as Đguras compostas por uma superfície de resposta ao lado de uma curva de nível, como será visto a seguir.

A Figura 1 apresenta a superfície de resposta e as curvas de nível que nos permite analisar a influência mútua dos fatores concentração do malte e a porcentagem de alginato de sódio sobre o rendimento da imobilização. A sua otimização é feita considerando-se os maiores valores de rendimento de imobilização. A Figura 2 mostra as superfícies de resposta e as curvas de nível que representam a perda ou redução da atividade da enzima relacionada aos fatores concentração do malte e porcentagem de alginato de sódio. $\mathrm{Na}$ análise destes grá $\mathbb{C}_{\mathrm{cos}}$ deve-se atentar para o fato de que a região ótima é aquela que corresponde aos menores valores de perda da atividade, por isso a análise é feita de uma forma diferenciada. A combinação das análises das Figuras 1 e 2 mostra que existem duas regiões para imobilização das amilases de malte de milho, uma à direita entre as concentração do malte de milho de 15 a 17,05 g.L $\mathrm{L}^{-1}$ (ou níveis 1 a 1,414 ), combinadas com valores entre a 0,25 a $0,1586 \mathrm{~g}$ (ou níveis $-0,5 \mathrm{a}-1,414)$ de massa de alginato de sódio; e outra a esquerda entre a concentração de malte de milho de 5 a 2,93 g.L $\mathrm{L}^{-1}$

Tabela 3. Resultados da avaliação ANOVA do modelo da inibição da atividade enzimática pela imobilização.

\begin{tabular}{lrrrcc}
\hline \multicolumn{1}{c}{$\begin{array}{c}\text { Fonte de } \\
\text { variação }\end{array}$} & $\begin{array}{c}\text { Soma } \\
\text { quadrática }\end{array}$ & $\begin{array}{c}\text { Graus de } \\
\text { liberdade }\end{array}$ & $\begin{array}{c}\text { Média } \\
\text { quadrática }\end{array}$ & $F_{\text {calc }}$ & $F_{\text {tab }}$ \\
\hline Regressão & 25244,9540 & 5 & 5048,9908 & 260,727 & 3,97 \\
Resíduos & 135,5554 & 7 & 19,3651 & - & - \\
Falta de ajuste & 44,2951 & 5 & 8,8590 & 0,194 & 19,3 \\
Erro puro & 91,2603 & 2 & 45,6302 & - & - \\
Total & 25380,5098 & 12 & - & - & - \\
\hline \multicolumn{5}{c}{$\%$ de variância explicável $=$} & 99,466 \\
\\
\% máxima variância explicável $=$ & 99,640 & \\
Coe冈ciente de determinação $\left(\mathrm{R}^{2}\right)=$ & 0,9947 \\
\hline
\end{tabular}

(ou níveis -1 a -1,414), combinadas com 0,35 a 0,4414 g (ou níveis 0,5 a 1,414) de massa do alginato de sódio.

A Figura 3 mostra as superfícies de resposta e as curvas de nível,utilizadas para relacionar a influência mútua dos fatores $\mathrm{pH}$ e concentração de malte sobre o rendimento da imobilização. Nota-se por esta \gura que um bom rendimento pode ser alcançado em uma ampla faixa na região de trabalho, não incluindo valores de concentração de malte de milho que desviem aquém de 3,75 g.L. $\mathrm{L}^{-1}$ (ou nível -1,25) para a esquerda e/ou além de 16,25 g. $\mathrm{L}^{-1}$ (ou nível 1,25) para a direita do seu eixo. A Figura 4 mostra as superfícies de resposta e as curvas de nível, que possibilitam a análise da relação da perda ou redução da atividade da enzima com os fatores $\mathrm{pH}$ e concentração do malte. Desta última \gura, nota-se que só é possível diminuir a perda em quase $100 \%$ nos valores extremos de concentração do malte e para qualquer $\mathrm{pH}$. Assim, pela combinação da análise das duas छguras, a concentração de malte de milho deve estar entre 5 g.L. $\mathrm{L}^{-1}$ e 3,75 (níveis entre -1 e -1,25) à esquerda e a 15 e 16,25 g.L $\mathrm{L}^{-1}$ (níveis entre 1 e 1,25) à direita, combinada com qualquer $\mathrm{pH}$ usado neste trabalho.

A Figuras 5 mostra as superfícies de resposta e as curvas de nível, para possibilitar a análise da influência mútua dos fatores porcentagem de alginato de sódio e $\mathrm{pH}$ sobre o rendimento da imobilização. A região onde se encontram os maiores rendimentos de imobilização é a correspondente aos valores da porcentagem de alginato de sódio de 0,25 até $0,4414 \mathrm{~g}$ (níveis entre $-0,5$ e 1,414 ) com o $\mathrm{pH}$ entre 6,6 e 4,83 (níveis entre 0,6 e -1,414). A Figura 6 mostra as superfícies de resposta e as curvas de nível, que relacionam a perda ou redução da atividade enzimática em relação aos fatores porcentagem de alginato e $\mathrm{pH}$. As análises desta Øgura mostram que a qualquer $\mathrm{pH}$ podem-se obter baixos valores de perda de atividade, mas só para valores da porcentagem de alginato de sódio entre 0,2 e 0,4 g (níveis entre -1 e 1), sendo melhor quando se aproxima do centro. Por esta combinação, a melhor condição seria entre 0,25 e $0,4 \mathrm{~g}$ (ou entre os níveis -0,5 a 1) para a porcentagem de alginato de sódio, combinado com o pH do meio entre 6,6 a 4,83. Biazus et al. (2006b) caracterizaram as amilases de malte de milho e obtiveram uma faixa ótima de $\mathrm{pH}$ entre 4,3 e 6, provavelmente o $\mathrm{pH}$ acima desta faixa também tenha contribuído com a redução da atividade das enzimas. Bayramoglu et al. (2004) obtiveram maiores rendimentos de atividade da amilase de $B$. licheniformis imobilizada em membrana a $\mathrm{pH}$ 6, coincidindo com o $\mathrm{pH}$ ótimo da enzima em estado livre. Day et al. (2003) caracterizaram a $\alpha$-amilase de $B$. circulans imobilizada em alginato de sódio e obtiveram 4,9 como $\mathrm{pH}$ ótimo. Já para a $\alpha$-amilase de cevada imobilizada em sílica gel, Lim et al. (2003) obtiveram como $\mathrm{pH}$ ótimo o valor de 4,5. Ambos os pHs estão na região do $\mathrm{pH}$ ótimo das amilases, citado pela literatura.

Continuando a otimização RSM para o método de imobilização de amilases de malte de milho por oclusão em matriz temos, por uma combinação das análises das Figuras 1 a 6, que a condição ótima é obtida quando se imobilizam as enzimas usando soluções de malte de milho a concentrações baixas de 5 g. $\mathrm{L}^{-1}$ até 3,75 e altas de 15 até 16,25 g. $\mathrm{L}^{-1}$, com pH do meio entre 4,83 e 6,6 e usando $4 \mathrm{~g}$ de alginato de sódio para cada $100 \mathrm{~mL}$ destas soluções de malte de milho. 

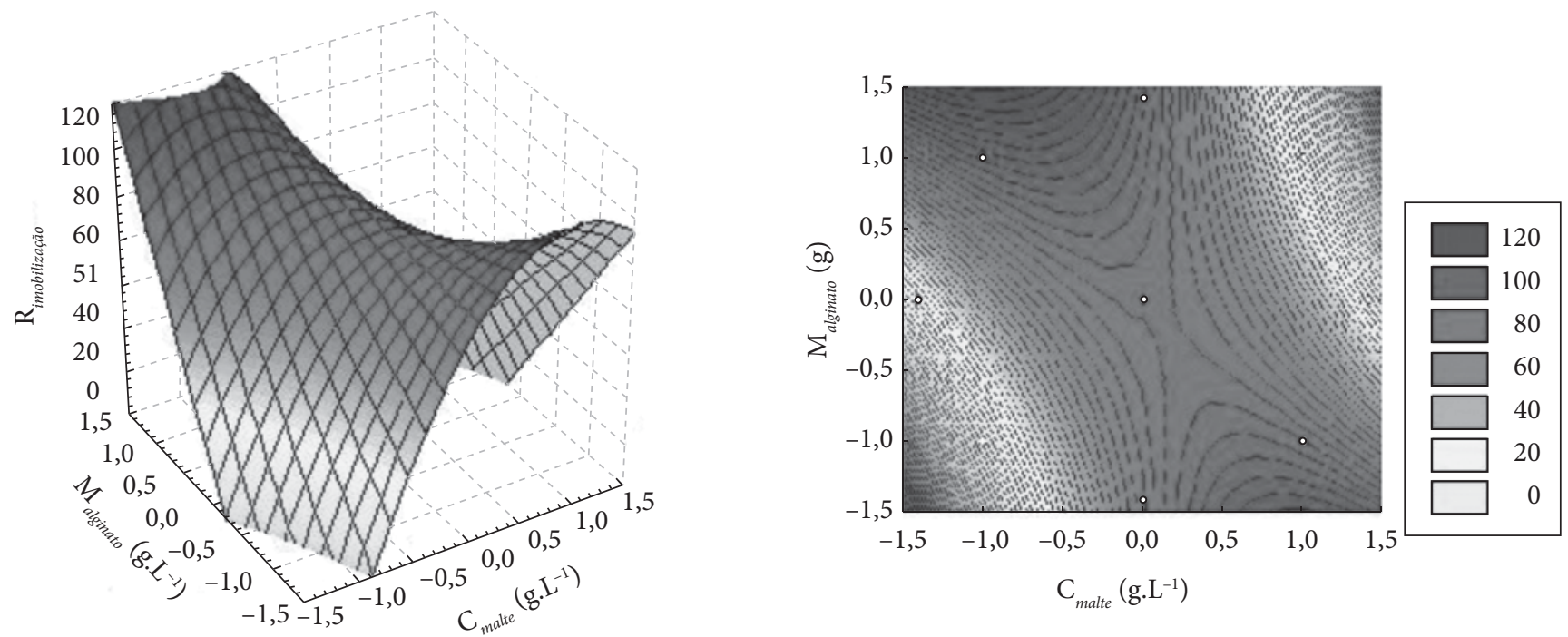

Figura 1. Superfície de resposta e curvas de nível que mostram o efeito mútuo da concentração do malte e da porcentagem de alginato de sódio sobre o rendimento da imobilização.
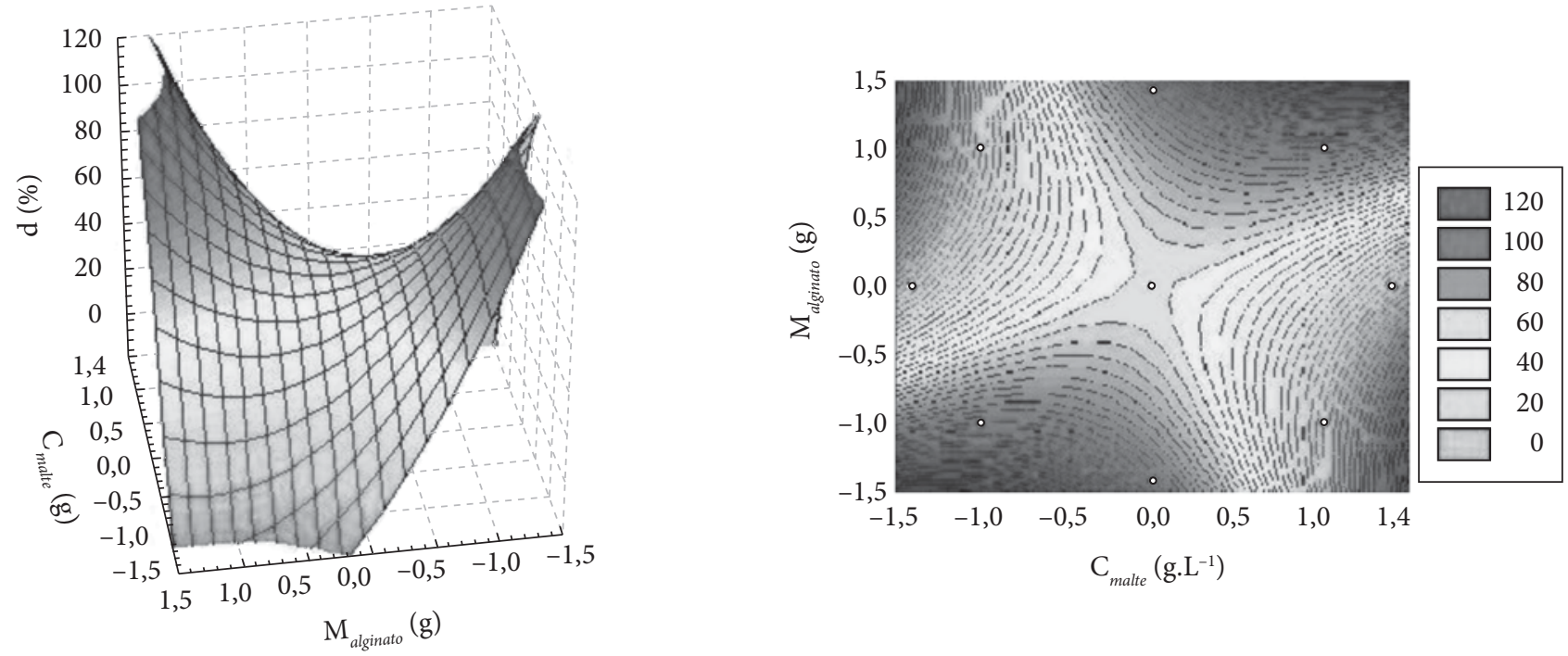

Figura 2. Superfície de resposta e curvas de nível para mostrar o efeito mútuo da concentração do malte e da porcentagem de alginato de sódio sobre a perda ou redução da atividade das amilases do malte de milho.
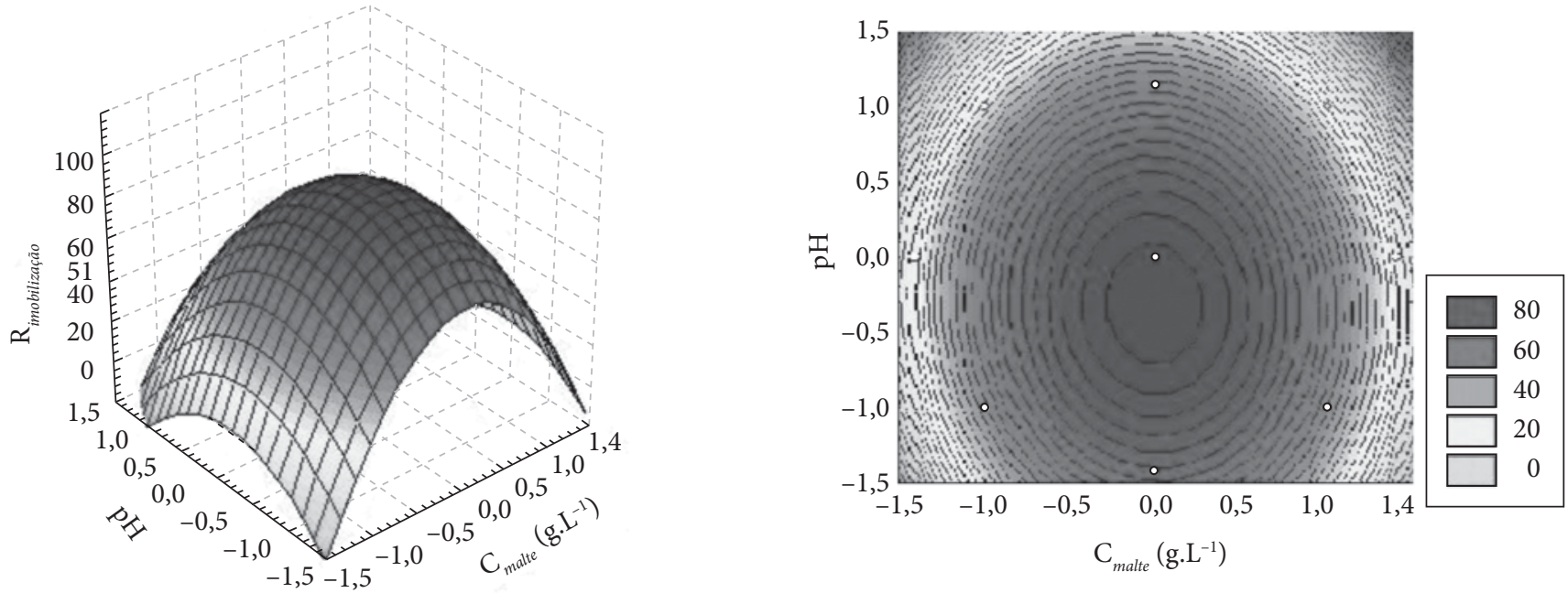

Figura 3. Superfície de resposta e curvas de nível para mostrar o efeito mútuo da concentração do malte e do pH sobre o rendimento da imobilização. 

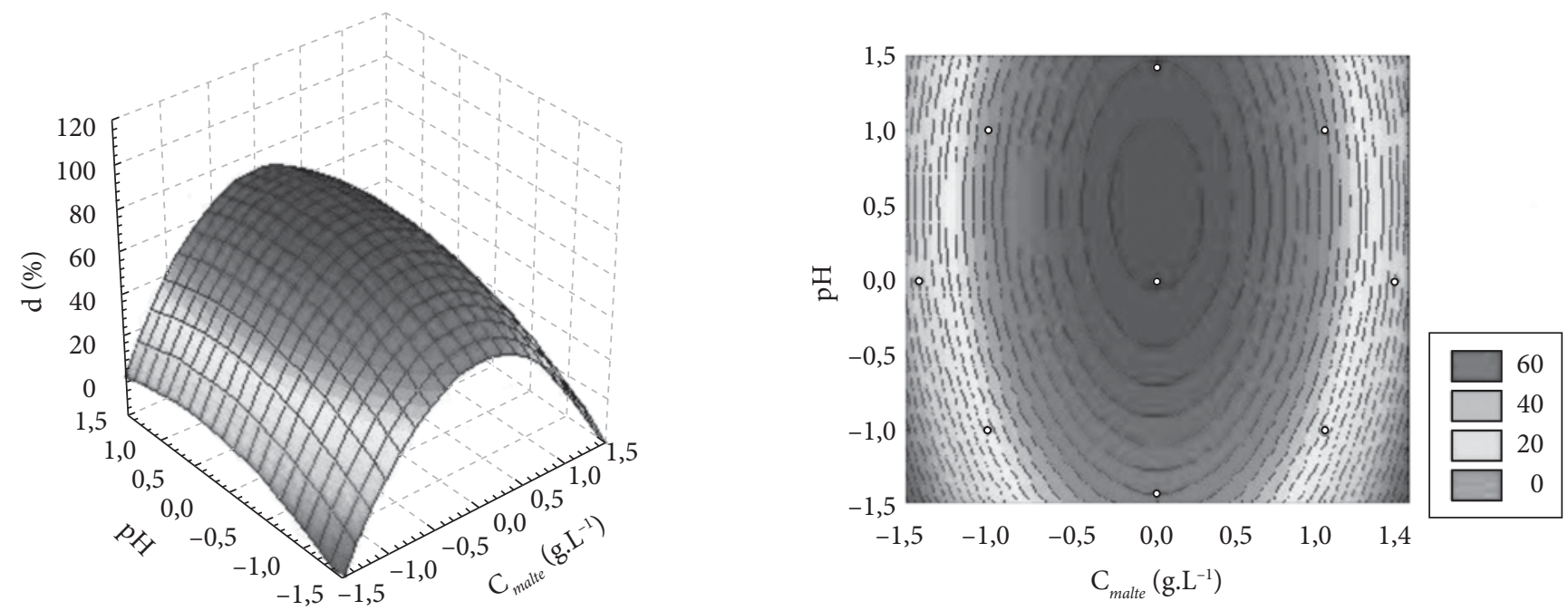

Figura 4. Superfície de resposta e curvas de nível para mostrar o efeito mútuo da concentração do malte e o pH sobre a perda ou redução da atividade das amilases do malte de milho.
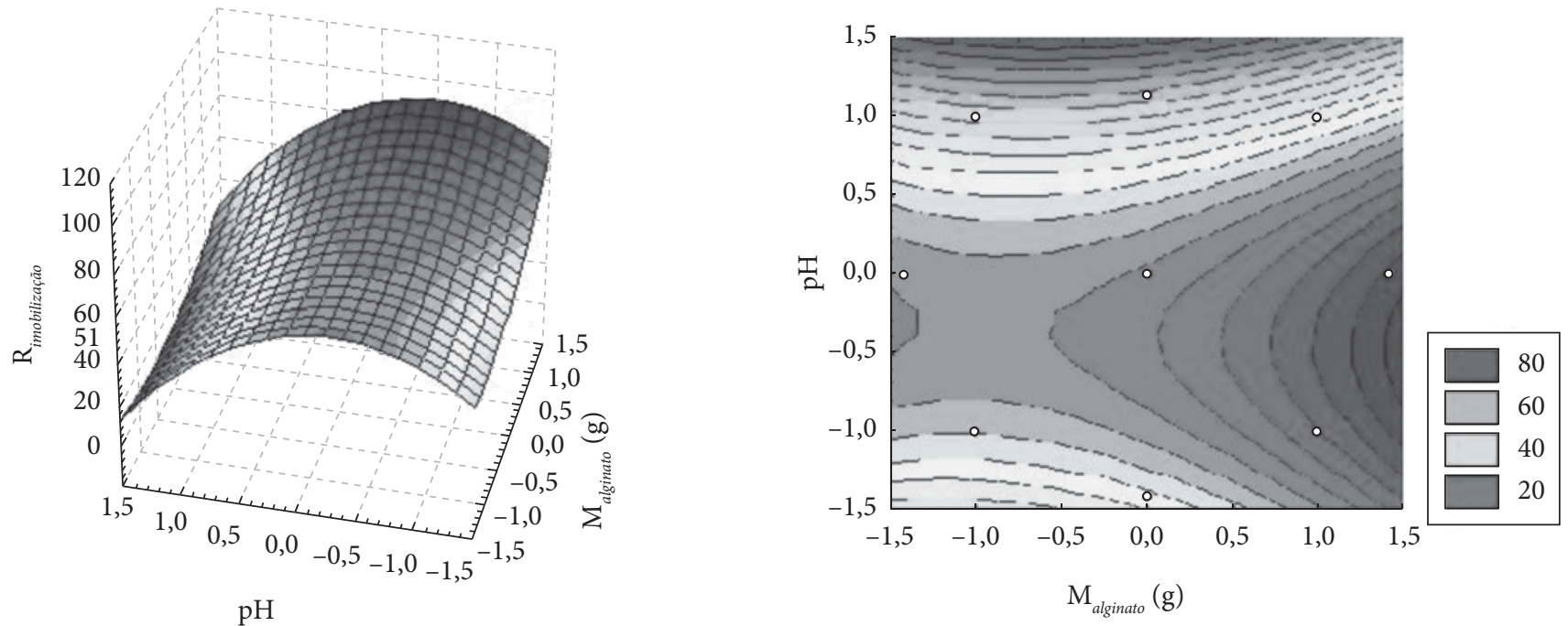

Figura 5. Superfície de resposta e curvas de nível para mostrar a influência mútua da porcentagem de alginato e do pH sobre o rendimento da imobilização de amilases do malte de milho.
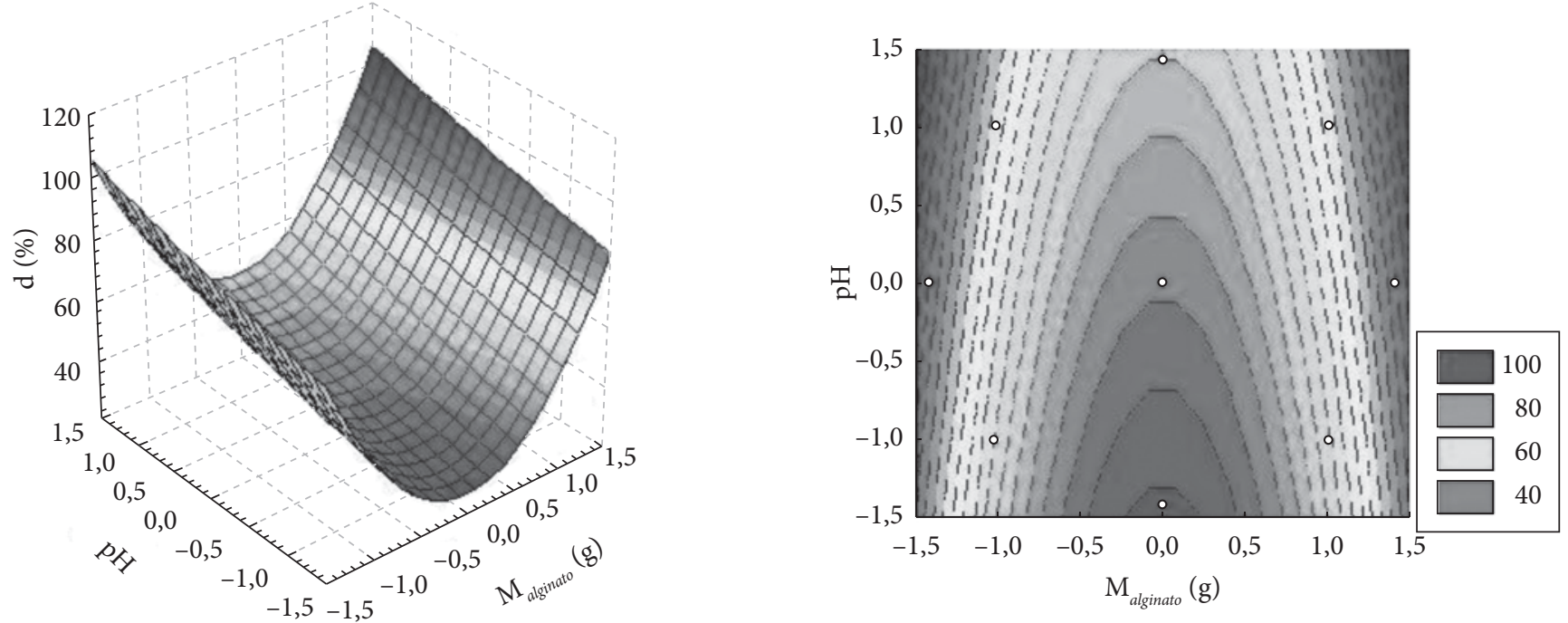

Figura 6. Superfície de resposta e curvas de nível para mostrar o efeito mútuo do pH do meio e da porcentagem de alginato de sódio sobre a perda ou a redução da atividade das amilases do malte de milho. 
Desta forma, torna-se possível obter amilases de malte de milho imobilizadas com boa atividade enzimática que podem ser usadas, livres da interação com o solvente e com maior estabilidade à inativação por fatores químicos, físicos ou biológicos que agem durante a sua estocagem ou durante os diversos processos de hidrólise de amido, além de facilitar a sua recuperação e reutilização após estes processos (DALLA-VECCHIA et al., 2004).

\section{Conclusões}

Os rendimentos das imobilizações foram superiores aos obtidos pela literatura. As melhores condições de imobilização das amilases de malte de milho obtidas pela metodologia RSM foram aquelas nas quais se imobilizaram as enzimas usando as soluções de malte de milho em duas faixas de concentração, uma entre 3,75-5 g. $\mathrm{L}^{-1}$ e outra entre $15-16,25$ g. $\mathrm{L}^{-1}$, com pH do meio entre 4,83 e 6,6 e utilizando-se $4 \%(\mathrm{~m} / \mathrm{v})$ de alginato de sódio nestas soluções de malte de milho. Nestas condições conseguiuse imobilizar $100 \%$ das enzimas contidas no malte de milho, com baixa inibição das mesmas. Assim, este trabalho mostrou condições ótimas para a imobilização das amilases de malte de milho, sem perder sua atividade enzimática, proporcionando ao mercado mais um biocatalisador que pode ser usado em processos industriais de hidrólise de amido.

\section{Agradecimentos}

Os autores agradecem ao PIBIC-UFS/CNPq e à FAPESP pela concessão das bolsas.

\section{Referências bibliográficas}

BARROS NETO, B.; SCARMINIO, I. S.; BRUNS, R. E. Como Fazer Experimentos: Pesquisa e Desenvolvimento na Ciência e na Indústria. $1^{a}$ ed. Campinas: EDUNICAMP, 2001. (Coleção Livros Textos).

BARROS NETO, B.; SCARMINIO, I. S.; BRUNS, R. E. Planejamento e Otimização de Experimentos. 1 ed. Campinas: EDUNICAMP, 1995. (Série Manuais).

BAYRAMOGLU, G.; YILMAZ, M.; ARICA, Y. Immobiilzation of a thermostable $\alpha$-amylase onto reactive membranes: kinetics characterization and application to continuos starch hydrolysis. Food Chemistry, v. 84, n. 4, p. 591-599, 2004.

BIAZUS, J. P. M. et al. Otimização da secagem do malte de Zea mays. Ciência e Tecnologia de Alimentos, v. 26, n. 4, p. 787-792, $2006 a$.

BIAZUS, J. P. M. et al. Caracterização da atividade amilásica do malte de milho (Zea mays). Acta Scientiarum, v. 28, n. 1, p. 13-19, 2006 b.

BIAZUS, J. P. M. et al. Study of amylases recovery from maize malt by ion-exchange expanded bed chromatography. Process Biochemistry, v. 41, n. 8, p. 1786-1791, 2006c.

BIAZUS, J. P. M. et al. Maximizing of production stages of malt from Zea mays. Brazilian Journal of Food Technology, v. special, p. 138-145, 2005a

BIAZUS, J. P. M. et al. Optimization of drying process of Zea mays malt to use as alternative source of amylolytics enzymes. Brazilian Archives of Biology and Technology, v. 48, special issue, p. 185-190, 2005b.

BORZANI, W. et al. Biotecnologia Industrial: Engenharia Bioquímica. 1 ed. São Paulo: Edgard Blucher Ltda, 2001. v. 2.
BRADFORD, M. M. A rapid and sensitive method for the quantitation of microgram quantities of protein. Utilizing the principle of protein-dye binding. Analytical Biochemistry, v. 72, n. 1, p. 248-254, 1976.

BRENA, M. B. et al. $\bigotimes$ iolation and reversible immobilization of sweet potato b-amylase on thiolsulfonate-agarose. Journal of Molecular Catalysis, v. 84, n. 3, p. 381-390, 1993.

DAY, G; SINGH, B; BANERJEE, R. Immobilization of a-Amylase Produced by Bacillus circulans GRS 313. Brazilian Archives of Biology and Technology, v. 46, n. 2, p. 167-177, 2003.

CASTRO, H. F; ANDERSON, W. A. Fine chemicals by biotransformation using lipases. Química Nova, v. 18, n. 6, p. 544-554, 1995.

CRUZ, A. B. Lipase de farelo de arroz: Extração, imobilização e aplicação. Campinas, 2000, 101p. Tese - (Doutorado em Engenharia de Alimentos), Faculdade de Engenharia de Alimentos, Universidade Estadual de Campinas - UNICAMP.

DALLA-VECCHIA, R.; NASCIMENTO, M. G.; SOLDI, V. Aplicações sintéticas de lipases imobilizadas em polímeros. Química Nova, v. 27, n. 4 , p. $623-630,2004$.

GASPARI, J. W.; GOMES, L. H.; TAVARES, F. C. A. Imobilização da inulinase de Kluyveromyces markianus para a hidrólise de extratos de Helianthus tuberosus L. Scientia Agrícola, v. 56, n. 4 suplemento, p. 1135-1140, 1999.

GOODENOUGH, P.; LAW, B. Enzymes for food biotechnology. BFE, v. 8, n. 12, p. 22-24, 1991.

KOURKOUTAS, Y. et al. Immobilization technologies and support materials suitable in alcohol beverages production: a review. Food Microbiology, v. 21, n. 4, p. 377-397, 2004.

LIM, H. L.; MACDONALD, D. G.; HILL, G. A. Hydrolysis of starch particles using immobilized barley $\alpha$-amylase. Biochemical Engineering Journal, v. 13, n. 1, p. 53-62, 2003.

MALCATA, F. X. et al. Immobilized lipase reactors for modi冈cation of fats and oils-A review. Journal of the American Oil Chemists Society, v. 67, n. 12, p. 890-910, 1990.

OLSON, N. F.; RICHARDSON, T. Immobilized enzymes in food processing and analysis. Journal of Food Science, v. 39, n. 3, p. 653-659, 1974.

PEREIRA, E. B.; ZANIN, G. M.; CASTRO, H. F. Immobilization and catalytic properties of lipase on chitosan for hydrolysis and esterification reactions. Brazilian Journal of Chemical Engineering, v. 20, n. 4, p. 343 - 355, 2003.

REGULY, J. C. Biotecnologia dos Processos Fermentativos. 1 ed. Pelotas: EDUFPel, 2000. v. 3.

ROBLE, N. D.; OGBONNA, J. C.; TANAKA, H. A novel circulation loop bioreactor with cells immobilized in loofa (Lu囚a cylindrical) sponge for the bioconversion of raw cassawa starch to ethanol. Applied Microbiology Biotechnology, v. 60, n. 3, p. 671-678, 2000.

SANTANA, J. C. C. Recuperação das enzimas $\alpha$ e $\beta$-amilases em sistema bifásico aquoso $\mathrm{PEG} / \mathrm{CaCl} 2$ para uso como biocatalizador amiláceos. Campinas, 200. 232p. Dissertação (Mestrado em Engenharia Química), Faculdade de Engenharia Química, Universidade Estadual de Campinas - UNICAMP.

SOARES, C. M. F. Otimização por planejamento experimental da imobilização de lípase em sílica de porosidade controlada na presença de estabilizante. Campinas, 2000. 107p. Dissertação (Mestrado em Engenharia de Alimentos), Faculdade de Engenharia de Alimentos, Universidade Estadual de Campinas - UNICAMP. 